\title{
THE SOCIAL BACKGROUND OF INFANCY : THE DOMESTIC ENVIRONMENT OF 471 OXFORD BABIES
}

\author{
BY \\ E. JEAN THWAITES, B.Sc.(Lond.), A.M.I.A. \\ From the Institute of Social Medicine, Oxford
}

(Received for Publication, August 22, 1949)

It is generally recognized that infant mortality is a sensitive index of social conditions, showing high rates where bad housing, overcrowding, and maternal neglect prevail. Although there has been an appreciable reduction in the rate in England and Wales which, 50 years ago, was 150 per 1,000 births, and is now less than 50, nevertheless the data available still indicate wide variations in the mortality in infancy, not only in different towns but also in different socio-economic groups. It is very probable that side by side with the disparities revealed by mortality statistics similar variations obtain in the growth and health of babies living under different social and environmental conditions.

Although the last century has witnessed vast social improvements, Chadwick's 'Report on the Sanitary Condition of the Labouring Population of Great Britain' (1842) still illustrates the factors which to-day have to be considered in preparing the social records of children in an enquiry such as the Oxford Child Health Survey.

\section{The Oxford Child Health Survey}

This survey was referred to in the Annual Report (1945) of the Institute of Social Medicine as an investigation which 'has been undertaken with a view to studying and comparing the health, development, and sickness experience of children in all social groups from the first weeks in life to the age of five years. The clinical and somatometric examinations are made at three-monthly intervals. At six-monthly intervals (from the age of six months) radiographic studies of skeletal development are included. As far as possible, both major and minor sickness episodes are also recorded. Parallel social, domestic, and economic studies are made in the course of regular home visits.'

Source and Nature of Data. The present paper is concerned with social studies only and should be considered against a picture of Oxford as a whole, such as is given in the "Survey of the Social Services in the Oxford District ' by the Barnett House Survey Committee (1938 and 1940). Oxford consists of a central university and shopping area; a large northern residential area; a large southern area where a high proportion of workers at Morris Motors and the Pressed Steel Company Limited (employing about 15,000 workers between them) are housed; and some slum areas near the stations and the canal.

The children, whose circumstances are here under review were born between 1944 and 1947, and were enrolled, under the age of six weeks, at eight of the ten infant welfare centres in Oxford and at the Oxford Mothercraft Clinic (a private clinic). The health visitors explained the purpose of the survey to the mothers who anticipated living in Oxford for the following five years, and those who wished to do so enrolled on a voluntary basis. There was thus a measure of selection in that only those mothers who were interested enough to attend welfare centres were drawn upon at this stage. Nevertheless, all social classes are represented.

After enrolment the children were immediately examined medically and measured by the paediatrician. Then the medical-social worker, who had been present at the interview, asked the mother if she might visit her to learn further particulars relevant to the home situation and the baby's health.

Home Visiting Technique. Although the purpose of home visits in a survey of this kind is to accumulate specific information, every effort was made to give an air of informality to the interviews. As far as possible the mothers - were encouraged to talk without prompting; where questions were needed, attempts were made to follow a natural thoughtsequence and leading questions were avoided. At the first visit the purpose of the Survey was again discussed in order to clear up any doubts or misunderstandings. 
In practice, information was then usually gleaned in the following order. First, the child's diet was discussed and, if he was not breast-fed, possible reasons for the mother's failure were considered. This led naturally to consideration of the mother's present health, her health during pregnancy and her own past history and family history, and so to her date of birth, her husband's date of birth, and the date of marriage. The husband's occupation was noted in order to assign the family to one of the Registrar-General's five social classes.

After explaining that we were interested to see whether the density of the household had any bearing on the sickness rate, particulars of the number of persons in the house were noted and compared with the number of rooms. From this point details relating to bathrooms, W.C.s, laundry facilities, and other domestic conveniences were taken up in natural sequence. Gardens and allotments were then discussed in turn, and, in passing, the amount of fresh air secured for the baby, and how he was said to be sleeping, were recorded.

Essential details relating to feeding and dates were written down at the time, but other information was memorized and entered later in order to make the interview a chat rather than an interrogation. In particular, details to assist in assessing ' maternal efficiency' have been observed and grouped under the following five headings: (1) State of child ; (2) state of home; (3) diet of child; (4) health of mother; (5) attitude of mother to child. Each of these was classified as 'good,' 'fair,' or 'poor,' and was checked at each of the subsequent sixmonthly visits, which were without appointment. During the home visits an assessment was also made of the house, involving observations on age, state of repair, ventilation, light, damp, and whether or not condemned.

The second visit, at six months, had the special object of obtaining details of the early weaning history. At a year, details of diet were again noted and this was therefore an appropriate time to ask the mother if she could give an account of the amount of money she was spending on food for the family. Information has been very readily obtained.

As a result of these three home visits during the baby's first year of life, the following particulars were recorded and have been made the basis of the present analysis:

Child's Personal Particulars: Name; sex; date of birth; address; clinic.

Family Particulars: Age of father; occupation of father; age of mother; occupation of mother; date of marriage; number in household; number of families in the house; number of adults in the house; number of children in the house; expenditure on food.

Housing Particulars: Type of house; condition of house; number of rooms available for each household; number of rooms in the house; household conveniences.

\section{The Family}

Social Class. According to the statistics published by the Registrar-General, there is definite evidence that the infant mortality rate has varied markedly in the past between the social classes. Hence it was desirable to take into account the social stratification of the family from which each baby was enrolled.

The Registrar-General's five social classes are based on the occupation of the father, and are : Social Class I, higher professional grades; Social Class II, lower professional and administrative grades; Social Class III, skilled occupations; Social Class IV, semi-skilled occupations; Social Class V, unskilled occupations.

The number of babies in each social group is given in Table 1.

TABLE 1

Distribution by Social Class of 471 Oxford Babies

\begin{tabular}{c|c|c}
\hline Social Class & Number & Percentage \\
\hline I & 33 & $7 \cdot 01$ \\
II & 43 & $9 \cdot 13$ \\
III & 319 & $67 \cdot 73$ \\
IV & 43 & $9 \cdot 13$ \\
V & 33 & $7 \cdot 01$ \\
\hline Total & 471 & 100 \\
\hline
\end{tabular}

For convenience social classes I and II and social classes $\mathrm{IV}$ and $\mathrm{V}$ respectively have been considered together. It was purely fortuitous that the number in each of these two groups was the same.

It will be seen from Table 2 that Oxford has a higher proportion of social class III and a lower proportion of IV-V than the country as a whole. This is reflected in the recruitment of the Child Health Survey where there is a preponderance of social class III. Mothers from this class provide the bulk of the attendances at the City's welfare centres and, apart from this, are more likely to volunteer to join a survey and are less likely to default than mothers belonging to class IV-V. Babies representing classes I-II have mainly been drawn from the Oxford Mothercraft Clinic.

The fact that the social classes in the Child Health Survey are not in the same proportion as those in 
TABLE 2

Distribution by Social Class

\begin{tabular}{|c|c|c|c|}
\hline \multirow{4}{*}{$\begin{array}{l}\text { Population of England and } \\
\text { Wales, Census 1931, } \\
\text { Occupied Male } \\
\text { City of Oxford, 1931 } \\
\text { Child Health Survey, } \\
-47 \quad \text {.. }\end{array}$} & \multicolumn{3}{|c|}{$\begin{array}{l}\text { Percentage in Each } \\
\text { Social Class }\end{array}$} \\
\hline & I and II & III & IV and V \\
\hline & $\begin{array}{l}16 \cdot 52 \\
15 \cdot 76\end{array}$ & $\begin{array}{l}49 \cdot 16 \\
57 \cdot 45\end{array}$ & $\begin{array}{l}34 \cdot 32 \\
26 \cdot 79\end{array}$ \\
\hline & $16 \cdot 14$ & $67 \cdot 73$ & $16 \cdot 14$ \\
\hline
\end{tabular}

the country as a whole does not, of course, invalidate comparisons between the classes.

Unemployment among the fathers of the children in the survey has been negligible.

The Age of the Parents. The age of the father at the time of the birth of the baby included in the survey ranged from 20 to 57 years. The average showed little difference between the social classes, being 34 years in I-II, 33 years in III, and 35 years in IV-V. The average for the fathers in all the social classes was 33 years.

The age of the mother at the date of the birth of the survey child (which may or may not be her first child) ranged from 19-45 years, the range being slightly more limited in social class I-II. The average age in each of the three groups was 30 years. The distribution pattern of the age of the mothers in this survey approximately follows that for the whole country. There are, however, fewer mothers under the age of 25 in the survey. This may, in part, reflect the fact that in general a higher proportion of illegitimate babies is born to young mothers, and these babies were not fully represented in the survey. There were no mothers over the age of $\mathbf{5 0}$ in the survey.

Duration of Marriage. On the social records used, the day, month, and year of birth and of marriage have been entered, but only the year has been transcribed on to the punch-cards used for analysis. In social classes I-II the duration of marriage ranged from 1 to 16 years and the average duration at the birth of the 'survey baby' was 5.75 years. In social class III the duration ranged up to 25 years, the average duration being $6 \cdot 73$ years. Eight of the 319 mothers in this class were unmarried. In social classes IV-V the duration ranged up to 21 years and the average duration was 6.89 years. Three of the 76 mothers in this group were unmarried.

The proportion of unmarried mothers in the survey is therefore 11 in 471 , or $2.3 \%$, whereas in England and Wales as a whole the proportion of illegitimate maternities was $9 \cdot 33 \%$ in 1945 , and for births registered in Oxford in 1945 the figure was $8.75 \%$. That there is a low representation of unmarried mothers in the survey is readily understandable, for the unmarried mother is more likely to go out to work and to lack the time to bring her baby for the examination required by the survey. In addition, a certain proportion of these children are cared for in institutions which are not covered by the survey, and a further number are adopted. There were only two adopted children.

Number of Surviving Children in the Family. Of the 471 families, 220 infants were only children at the time of enquiry, although not necessarily the firstborn as, in this instance, stillbirths and siblings who had not survived were not considered. There were two children in each of 143 families (including two families with twins in the survey); four to nine children in $\mathbf{4 5}$ families, and more than ten surviving children in three families. This follows closely the pattern of distribution by number of surviving previous children in England and Wales as a whole.

Occupation of the Mother. Of the mothers of the 471 children, 33 were at work before the child's first birthday. Of these 33 , four were from social classes I-II, 12 from social class III, and 17 from social classes IV-V.

Twenty-five of these mothers were able to work without being separated from the child, either because the baby accompanied the mother to work (as was the case with the 11 mothers who did daily domestic work and the general practitioner who took her baby with her on her rounds), or because the mother lived and worked on the premises. Four of these mothers assisted relatives with shops: one of these was a fish-and-chip shop and three were small general stores. It was noteworthy on later enquiry into the children's feeding, that the children of the last three mothers 'didn't eat well ' at meal times. It was soon discovered that they were in the habit of helping themselves to biscuits in the shop whenever they felt inclined.

Eight mothers had to leave their babies in the care of another person while they went out to work. One mother worked in a laundry when her baby was six months old, as her husband had lost several fingers in a factory accident. She left her son in the care of her own parents and her husband and, far from being neglected, the child was spoiled. The other seven mothers who had to go to work, leaving their children, were unmarried and all were working before the child was six months old. Five left the child with relatives, one with a foster 
mother, and one took the child to a day nursery. There were four other unmarried mothers in this series. One worked as a resident domestic help, returning with her baby to her previous employer; one, who was living with the father of the baby, went out to domestic work, taking the child with her; one later married the father of the child. The remaining mother did not at first go out to work but stayed at home to look after the house whilst her own mother went out to work. She has since had a second illegitimate baby (her third pregnancy) for whom adoption has been arranged. Her first child (who is in the survey) now attends a day nursery while the mother works.

In this series only one child was taken to a day nursery before the age of one year. In any analysis of the subsequent social records of these children, a much higher number will be found to be attending day nurseries.

\section{Housing and Amenities}

The housing problem is too well known to require re-statement. Oxford, indeed, is fortunate in that not one of its houses was lost through enemy action, but, against this, is the fact that the population of Oxford has expanded rapidly. It is estimated that the population is more than double the 1901 figure of 49,000 . In common with the rest of the country, building in Oxford was virtually at a standstill during the war years. In 'Oxford Replanned' (1948), Mr. Sharp has estimated that ' some 6,000 new dwellings are required in Oxford to meet the present and early needs of the people at present living or working in the city, without any consideration whatsoever of the possibility of future growth.'

Number of Family-Units Living in the House. For the purpose of this study, the family-unit has been taken to include only the following: $(a)$ the survey baby, $(b)$ the parent or parents, $(c)$ the siblings, if any. The 'household' is the housekeeping unit in which the survey family-unit lives. For instance, if the survey family is living at the same address as the maternal grandparents, and the housekeeping arrangements and living rooms are communal, this establishment is classified as one 'household,' but two 'family-units.' Similarly, a friend or lodger who was catered for and was thus part of the one household would be considered as an extra familyunit. On these principles the number of familyunits in the whole house has been recorded. It will be realized that multiple family-units do not necessarily indicate multiple 'households,' but it was felt to be of interest to note whether or not the survey family was living alone because of the possible implications in child management. For instance, the fact that there are others in the house may have some effect on how the baby sleeps.

During the three visits in the first year, the mother has been asked how the child sleeps, and at the age of one year an attempt has been made to assess this as 'good,' 'fair,' or 'poor.' This is an arbitrary value as it is necessarily based on the mother's statements, but the length of time the child sleeps during the day and at night was recorded, the mother's comments on the soundness of sleep or frequent waking at night being duly taken into consideration. It was noted that, of the mothers who stated that their children were not sleeping well, the majority ( $18 \%$ compared with $10 \%$ ) were living where other people, apart from the immediate family, were occupants of the house. It can well be imagined that it is more difficult for a mother to break her child of bad sleeping habits when these have been aggravated by picking up the child each time he cries in order to avoid upsetting other occupants of the house.

Table 3 indicates that only $45.4 \%$ of the familyunits had a home to themselves. The average number of family-units per house was 1.68 in social classes I-II, 1.66 in social class III, and 1.98 in social class IV-V. The majority of familyunits who were sharing houses were living with the baby's grandparents while trying to find a home of their own. The disadvantage of the dual regime for the baby has to be offset against the probability of help with the housework for the mother. On the record forms a note has been made whether or not the mother has had any help with the housework, but the results have not been analysed in bulk as it has been difficult to draw the line between the different types of help this term might cover. For instance, at one end of the scale it may refer to a household which has a nanny and domestic help, and at the other end of the scale to the husband helping to dry the supper dishes. Incidentally, the mothers' comments on the help their husbands give have varied greatly. Some cook the Sunday joint; some do nothing. The wife of a chef, when asked if he did any cooking at home, said that she would not let him do so as he left such a trail of washing-up behind him. 'Mass Observation Bulletin' (June, 1948) stated that of its panel, nine out of ten male members of middle-class households expected to help with domestic work, and nine out of ten women thought it right that they should do so. Where, after her confinement, the mother has been able to have a home help this has been much appreciated.

Number of Persons in the House. Note was made of the number of children and the number of adults 
TABLE 3

One family-unit per House or Self-contained Flat

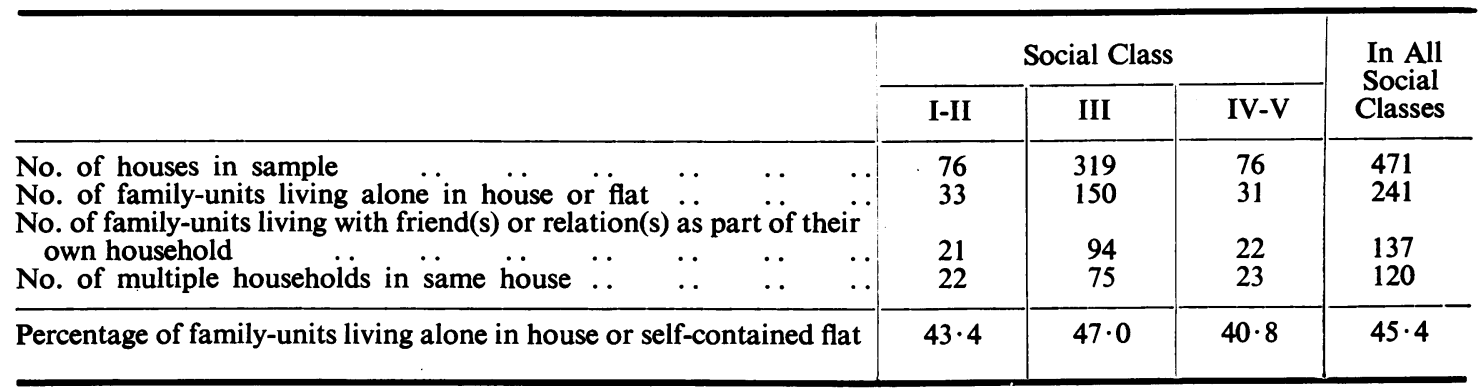

in both the household and the house. The number of persons in the house is shown in Table 4. These figures give some indication of the number of persons who had to share the same lavatory and other amenities.

Table 4 shows that the average number of persons per house in all social classes is 5.6. In the Manchester Billeting Survey (1945) the average number of persons per occupied house was $3 \cdot 25$. Data from the last census (1931) gives the average for Oxford County Borough Council as $4 \cdot 10$ then; for Manchester Borough Council as $4 \cdot 10$; for England and Wales as a whole as $4 \cdot 17$. On the other hand, the rooms per occupied dwellings are given as 5.67, $4 \cdot 72$, and 5.07 respectively for that date, whereas, considering the Child Health Survey homes only, the average number of rooms per house was 6.42 in social classes I-II, $5 \cdot 22$ in social class III, and $5 \cdot 13$ in social classes IV-V.
Density (Number of Persons per Room). As might be expected, the density at which families were living was highest in the lower social classes, the average number of persons per room being 0.83 in social classes I-II, 1.06 in social class III, and 1.31 in social classes IV-V. Data from the 1931 census give the average number of persons per room as 0.72 in the Oxford County Borough, as 0.87 in the Manchester County Borough, and as 0.83 in England and Wales as a whole, whereas the average in the Child Health Survey for all social classes has risen to 1.06 persons per room.

Table 5 shows the proportion of families living at different densities and the difference between the social classes is evident. When the household only is considered a higher percentage of families is living at a density of more than one person per room than when the whole house is considered, reflecting the fact that 11 families were each living in one

TABLE 4

Distribution by Number of Persons in the House

\begin{tabular}{|c|c|c|c|c|c|c|c|c|c|c|c|}
\hline \multirow{2}{*}{\multicolumn{8}{|c|}{ No. of Persons (Adults and Children) }} & \multicolumn{3}{|c|}{ Social Class } & \multirow{2}{*}{$\begin{array}{c}\text { All Social } \\
\text { Classes }\end{array}$} \\
\hline & & & & & & & & \multirow{2}{*}{$\begin{array}{r}\text { I-II } \\
50 \\
24 \\
1 \\
1\end{array}$} & \multirow{2}{*}{$\begin{array}{r}\text { III } \\
212 \\
101 \\
5 \\
1\end{array}$} & \multirow{2}{*}{$\begin{array}{c}\text { IV-V } \\
30 \\
41 \\
3 \\
2\end{array}$} & \\
\hline $\begin{array}{ll}2-5 & \ldots \\
6-10 & \cdots \\
11-15^{*} & \cdots \\
16^{*} \text { and over }\end{array}$ & $\begin{array}{l}\ldots \\
\cdots \\
\cdots \\
\cdots\end{array}$ & $\begin{array}{l}\cdots \\
\cdots \\
\cdots\end{array}$ & $\begin{array}{l}\cdots \\
\cdots \\
\cdots\end{array}$ & $\begin{array}{l}\cdots \\
\cdots \\
\cdots \\
\cdots\end{array}$ & $\begin{array}{l}\cdots \\
\cdots \\
\cdots\end{array}$ & $\begin{array}{l}\cdots \\
\cdots \\
\cdots\end{array}$ & $\begin{array}{l}\cdots \\
\cdots \\
\cdots\end{array}$ & & & & $\begin{array}{r}292 \\
166 \\
9 \\
4\end{array}$ \\
\hline \multicolumn{4}{|c|}{ Total no. of survey families .. } & . & . & - & .. & 76 & 319 & 76 & 471 \\
\hline \multicolumn{5}{|c|}{ Average no. of persons per house .. } & $\cdots$ & $\cdots$ & $\cdots$ & $5 \cdot 3$ & $5 \cdot 3$ & $6 \cdot 7$ & $5 \cdot 6$ \\
\hline
\end{tabular}

* The two families where there were 37 persons in one house were 'squatters' who took over an empty hotel. The family living where there were 12 persons to a building were squatters in the hotel annexe.

The family living where there were 22 persons in the house, was that of a housemaster at a boys' preparatory school.

The family living where there were 19 persons was one of four adults and an illegitimate child, living in three rooms in an old tenement house shared by four families consisting of twelve adults and seven children living in the nine rooms.

The family living where there were 14 persons in a house was one of four people (children aged 41 and 1 year) living in a bed-sittingroom at the top of an old tenement house where six families (14 persons) lived in seven rooms. 
TABLE 5

Distribution by Number of Persons per Room per cent.

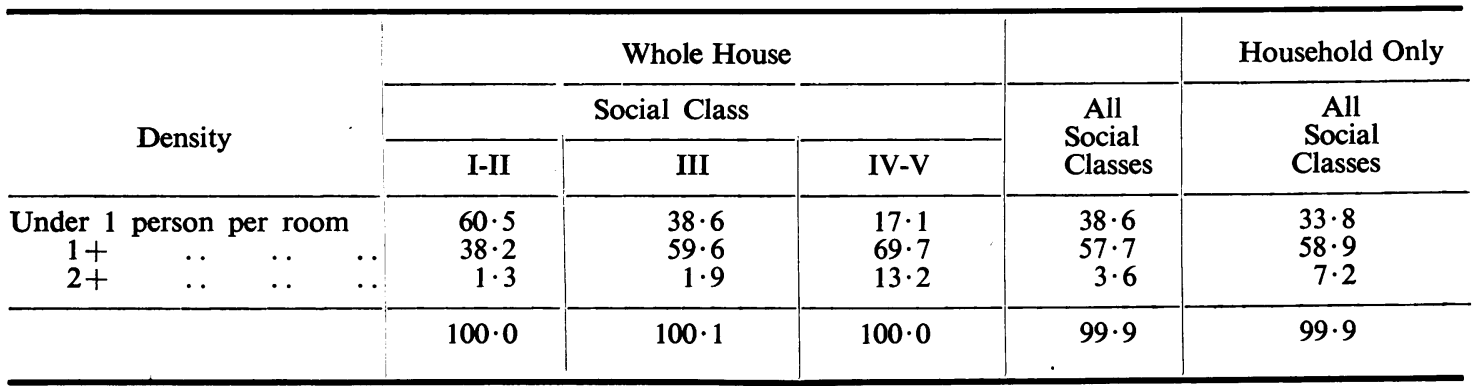

bed-sitting-room, in houses not otherwise exceptionally overcrowded. Seven families were living at three to the one room, two families at four to the one room, and two families at five to the one room.

Type of Housing. In appraising housing the standards used were, of necessity, personal standards, but individual differences of opinion were eliminated as far as possible, as one social worker only was engaged in the survey at one time.* Assessments were re-checked at the subsequent visits and, in cases of doubt, as with the older and more dilapidated houses, the opinion of the Sanitary Inspector was sought as a further countercheck.

Approximately half the houses in the survey were comparatively new. Of the total number, 205 were built before 1900; 33 were built between 1900 and $1920 ; 230$ were built after 1920. Two were unclassified. It was noted whether or not the house was condemned, but at present this has no strong significance as some houses in reasonably good condition were technically condemned before the war for purposes of town planning. Others, now in less good condition, are not yet condemned, for it is useless to condemn a house if there is no immediate prospect of re-housing the occupants. A special entry was made when a house was lowlying, in an area subject to flooding, or on the hills on the outskirts of the town, but as the variation is only between 200 and 350 feet above sea-level these notes have not been analysed.

State of Repair. This has been assessed as ' fair' when only minor repairs would have been required to put the house in order, and 'poor' where more extensive work was necessary. Frequently those houses classified as being in poor repair were condemned before the war, and extensive repairs are not therefore contemplated.

* For the period 1944-46 the social reporting was in the hands of Miss Elisabeth J. Williams. After a month of joint work the reporting has been the responsibility of the writer.
VENTILATION. In assessing ventilation note was taken of the size of the rooms, the size and position of windows for cross ventilation, and whether the house had through ventilation or whether it was built back to back. Where the potential ventilation has been good, but windows seldom opened, the ventilation from the point of view of housing details has been classed as good, but 'fresh air in relation to the baby' has been down-graded. The only back-to-back houses in this series were some old cottages in Wolvercote. The general picture for Oxford is clearly much more favourable than that obtaining, for instance, in a northern industrial town or in many parts of London.

LIGHT. In the assessment of lighting, this was classed as ' fair ' where the side of the room appeared dim, and as 'poor' where the lights had to be on during the day or where, but for economy, it would have been an advantage to have artificial lighting during the day. The majority of the houses were lit by electricity. $\dagger$

DAMP. The mother was particularly asked whether the house was damp at the first visit and after the first winter, and if she maintained that there was no damp, her statement was accepted. If, however, she said the house was damp, this was investigated and recorded as 'ground damp,' 'damp walls,' or actual 'leaks,' and, where necessary, this was confirmed with the Sanitary Inspector. No attempt at measuring the actual extent of the damp has yet been made. Of the 471 houses, 40 were recorded as having ground damp, 100 were recorded as having damp walls, and 18 as having actual leaks. Flooding in the spring of 1947 also led to the temporary recording of damp, as many of the houses in the central area had flooded basements.

The analysis of the housing conditions has been

$\dagger$ The three visits were at different times of the year. 
TABLE 6

Distribution in RESPECT OF REPAIR, VentILATION, Light and Damp: All Social Classes

\begin{tabular}{|c|c|c|c|}
\hline & Good & Fair & Poor \\
\hline $\begin{array}{l}\text { Repair } \\
\text { Ventilation } \\
\text { Light }\end{array}$ & $\begin{array}{l}74 \cdot 5 \% \\
76 \cdot 2 \% \\
74 \cdot 5 \%\end{array}$ & $\begin{array}{l}20 \cdot 6 \% \\
21 \cdot 7 \% \\
22 \cdot 3 \%\end{array}$ & $\begin{array}{l}4 \cdot 9 \% \\
2 \cdot 1 \% \\
3 \cdot 2 \%\end{array}$ \\
\hline Damp & $\begin{array}{l}72 \cdot 8 \% \\
\text { (i.e. no } \\
\text { damp) }\end{array}$ & \multicolumn{2}{|c|}{$\begin{array}{c}27 \cdot 2 \% \\
\text { (i.e. any form } \\
\text { of damp) }\end{array}$} \\
\hline
\end{tabular}

summarized in Table 6. As would be expected, the quality of the houses in respect of repair, ventilation, light, and damp was poorer in the lower social classes.

Council Houses. At the time of the original enquiry, 53 of the families were living in Council houses and 409 in houses built by private enterprise (nine unclassified). Any later analysis will show a higher proportion of Council houses, reflecting re-housing in the prefabricated houses on the new estates, in addition to re-housing in the older Council houses: Only one family from social class I-II lived in a Council house.

Flats and Tenements. Thirty-two homes were self-contained flats, either built as such or converted, and four homes were in tenement buildings.

Household Conveniences. These are analysed as percentages of the sample in Table 7.
BATHRoOMS. As will be seen from Table 7, 70\% of the families had access to a bathroom (the proportion again varying with the social class). In addition, many families managed with a zinc bath in the scullery, with water heated in the copper, for all the houses in this series had water from the main or a tap in the house. Where a small old house had a built-in bath added, this again was often in the scullery which, in many cases, was a later addition to the house, built on at the back.

Baths were, however, out of the question for any family living in rooms at the top of an old house where the only water tap was down in the basement. One mother carrying water under these circumstances fell downstairs and had a miscarriage. She has since been re-housed in a 'prefab' and the all-round standard of cleanliness has risen considerably. The increase in the cleanliness of the children is not so great as the increase in the cleanliness of the house. This is as would be expected, for when water was a more prized commodity, the children came first and an effort was made to keep them reasonably clean, though not nearly as much effort was put into cleansing the two shabby and overcrowded rooms. Since re-housing over a year ago, the new home has been kept at a good standard of cleanliness, and the children are delighting in playing in a garden for the first time.

It is not possible to make comparisons between the homes of the children in the survey and those in other selected areas of the country, but the Medical Officer of Health for Manchester has

TABLE 7

Household CONVENIENCES

\begin{tabular}{|c|c|c|c|c|c|c|}
\hline Bathroom & $\begin{array}{l}\text { Bathroom per family } \\
\text { Bathroom shared .. } \\
\text { No bathroom } \quad .\end{array}$ & $\begin{array}{l}\ldots \\
\cdots \\
\cdots \\
.\end{array}$ & $\begin{array}{l}. \\
\cdots \\
\cdots\end{array}$ & $\begin{array}{l}. \\
\cdots \\
\cdots\end{array}$ & $\begin{array}{l}\ldots \\
\cdots \\
\cdots\end{array}$ & $\begin{array}{r}62 \cdot 5 \% \\
7 \cdot 7 \% \\
29 \cdot 8 \%\end{array}$ \\
\hline Laundry facilities & $\left.\begin{array}{l}\text { Constant hot water } \\
\text { Airing cupboard } \\
\text { Outdoor drying } \\
\text { Less one of the above } \\
\text { Less two or three of the }\end{array}\right\}$ & $\begin{array}{c}\cdots \\
\ldots \\
\text { a above }\end{array}$ & $\cdots$ & $\begin{array}{l}\cdots \\
\cdots \\
\cdots\end{array}$ & $\begin{array}{l}\cdots \\
\cdots \\
\cdots\end{array}$ & $\begin{array}{r}43 \cdot 9 \% \\
51 \cdot 6 \% \\
4 \cdot 5 \%\end{array}$ \\
\hline Cooking facilities & $\begin{array}{ll}\text { Gas cooker } & . \\
\text { Electric cooker } & \ldots \\
\text { Other methods } & .\end{array}$ & $\begin{array}{l}\cdots \\
\cdots \\
\cdots\end{array}$ & $\begin{array}{l}\cdots \\
\therefore\end{array}$ & $\begin{array}{l}\cdots \\
\cdots\end{array}$ & $\begin{array}{l}\cdots \\
\cdots \\
\cdots\end{array}$ & $\begin{array}{r}59 \cdot 7 \% \\
37 \cdot 1 \% \\
3 \cdot 1 \%\end{array}$ \\
\hline Sanitation & $\begin{array}{ll}\text { Indoor } & \ldots \\
\text { Outdoor only } & \ldots\end{array}$ & $\begin{array}{l}\cdots \\
\cdots\end{array}$ & $\begin{array}{l}. \\
\cdots\end{array}$ & $\begin{array}{l}\ldots \\
\ldots\end{array}$ & $\begin{array}{l}\cdots \\
\cdots\end{array}$ & $\begin{array}{l}61 \cdot 8 \% \\
38 \cdot 2 \%\end{array}$ \\
\hline Larder & $\begin{array}{l}\text { Larder or refrigerator } \\
\text { No larder or refrigerato }\end{array}$ & $\ddot{\mathrm{r}}$ & $\begin{array}{l}. \\
\cdots\end{array}$ & $\begin{array}{l}\cdots \\
\cdots\end{array}$ & $\begin{array}{l}\ldots \\
\ldots\end{array}$ & $\begin{array}{l}65 \cdot 2 \% \\
34 \cdot 8 \%\end{array}$ \\
\hline Garden & $\begin{array}{l}\text { Garden } \\
\text { No garden }\end{array}$ & $\begin{array}{l}\ldots \\
\cdots\end{array}$ & $\begin{array}{l}. \\
\cdots\end{array}$ & . & $\begin{array}{l}\cdots \\
\cdots\end{array}$ & $\begin{array}{r}91 \cdot 1 \% \\
8 \cdot 9 \%\end{array}$ \\
\hline
\end{tabular}


kindly supplied an extract from a Billeting Survey (1945) giving the percentage of occupied houses having baths. This varied from $15.03 \%$ in the central area to $84.94 \%$ in the southern area, with an average of $59.14 \%$ for the total Manchester area,* whereas the percentage of the Child Health Survey homes with baths was $70 \cdot 28$.

LAUNDRY FACILITIES. ' Good' laundry facilities were taken to mean that the following were available: (1) Constant hot water, either heated by a fire boiler, a copper or an immersion heater; (2) an airing cupboard; (3) drying space, i.e. yard or garden.

'Fair' laundry facilities indicate that one of these facilities was lacking; often the airing cupboard, for, although 204 families had good laundry facilities, 270 had constant hot water. As can be imagined, where there is no airing cupboard and there is a baby in the house, napkins are constantly draped around for airing and usually the only fire is in the living room-which may also be the kitchen.

'Poor' laundry facilities were taken to mean that at least two of the three facilities were lacking.

SoAP. When the survey was first started a double soap ration was allowed only for infants up to the age of one year. At the end of 1947 this concession was extended until the infant's second birthday, and this, though belated, was much appreciated by the mothers who had all been maintaining that there was far more washing to do in the second year than in the first year. This is readily understandable, for the infant's peak period for starting to crawl (interpreted as any form of locomotion) is between 9 and 10 months. In a series of 334 children, $37.7 \%$ were said by their mothers to have taken their first steps by the age of 12 months, and though $94.9 \%$ had taken their first steps by the age of 18 months this by no means implied that the child had habitually assumed an upright posture at this stage. Also, the child cannot be relied upon to be clean and dry during the day and can be trusted still less to be dry at night, as Table 8 shows. For interest the infants were divided by sex, and the superiority of the girls over the boys in this respect is shown to be statistically significant (Table 8). These figures must be interpreted as being on the optimistic side, as they are based on information given by the mothers at the six-monthly clinical examinations, and ignore the occasional lapses afterwards.

* Manchester water is very soft, total hardness (as $\mathrm{CaCO}_{3}$ ) being about 3.6 parts per 100,000 . On the other hand, atmospheric pollution is high, the mean monthly deposit varying from 10.01 to 35.36 tons per month per square mile according to the district of Manchester (M.O.H. Report, 1946). The Oxford water supply is hard, total hardness being given as 22 parts per 100,000 , but the atmosphere shows such a small degree of pollution that no regular readings are taken (M.O.H. Report, 1946).
TABle 8

\begin{tabular}{|c|c|c|c|c|c|c|}
\hline & \multicolumn{2}{|c|}{ Boys } & \multicolumn{2}{|c|}{ Girls } & \multicolumn{2}{|c|}{ Both Sexes } \\
\hline & No. & $\%$ & No. & $\%$ & No. & $\%$ \\
\hline $\begin{array}{c}\text { Clean and dry- } \\
\text { day } \\
\text { At } 1 \text { year } . . \\
\text { At } 18 \text { months }\end{array}$ & $\begin{array}{l}24 \\
82\end{array}$ & $\begin{array}{l}13 \cdot 8 \\
47 \cdot 1\end{array}$ & $\begin{array}{r}30 \\
100\end{array}$ & $\begin{array}{l}18 \cdot 8 \\
62 \cdot 5\end{array}$ & $\begin{array}{r}54 \\
182\end{array}$ & $\begin{array}{l}16 \cdot 2 \\
54 \cdot 5\end{array}$ \\
\hline $\begin{array}{c}\text { Clean and dry- } \\
\text { night } \\
\text { At } 1 \text { year .. } \\
\text { At } 18 \text { months }\end{array}$ & $\begin{array}{r}3 \\
26 \\
\end{array}$ & $\begin{array}{r}1.7 \\
14.9 \\
\end{array}$ & $\begin{array}{r}8 \\
33 \\
\end{array}$ & $\begin{array}{r}5 \cdot 0 \\
20 \cdot 6\end{array}$ & $\begin{array}{l}11 \\
59 \\
\end{array}$ & $\begin{array}{r}3 \cdot 3 \\
17 \cdot 7 \\
\end{array}$ \\
\hline Total sa & 174 & $100 \cdot 0$ & 160 & $100 \cdot 0$ & 334 & $100 \cdot 0$ \\
\hline
\end{tabular}

Sanitation. The majority of homes had indoor sanitation. Eleven homes had indoor and outdoor sanitation. In this series all had water closets, for all the babies started life in the town. Some later moved out into the country and still remained in the survey, so that subsequent analyses will show a small proportion of earth or chemical closets. No note has been made of how many people shared one lavatory, but, indirectly, some impression can be gained from the tables, given earlier, which indicate the number of families and individuals in one house.

LARDERS. In spite of the relatively high proportion of larders, the impression gained is that the majority of mothers were in the habit of shopping daily. No specific records have been made on this subject, but those who have commented have mentioned that they shopped daily for vegetables in particular. The prefabricated bungalows are supplied with built-in refrigerators, but otherwise refrigerators were exceptional.

GaRdens and Allotments. As is shown in Table 7, 91\% or 429 families had gardens and of these, at the time, 190 grew some vegetables. In addition, 42 families had allotments when first asked. Of the families without a garden, a proportion had backyards, which is a factor when considering how much time the child spends out of doors. Many of the old houses, however, which are built in rows, have back doors which are so narrow that a pram cannot be taken into the backyard or garden, and, as the front door opens straight on to the street, the pram has to be put on the pavement.

\section{Cost of Food}

The mother was not asked to work out how much she was spending on food for her family until the 
baby was at least a year old, and this request was always framed in such a manner that she could have refused quite easily. In fact, there were only two point-blank refusals: once when the mother said the cost of food would be 'too high' and once where the family was obviously living a hand-tomouth existence and the simple arithmetic involved was said to be too difficult.

Even so, figures have not yet been obtained for all families. There are a number of reasons for this. The largest group consists of those mothers who ' forgot' (which is understandable where there is a gap of six months between the visits), and who will later have the figures for us. Another group includes families in which the paternal grandmother was doing the housekeeping for all, and the mother felt it would not be politic for her to make these enquiries. A third small group has been omitted because a substantial proportion of food has not been paid for at market prices; for instance, where the father owns a small shop, or where supplementary food is brought home as a perquisite, particularly from the colleges.

It was noted if vegetables were grown, either on an allotment or in the garden, and whether hens were kept. One or two mothers kept goats, one having been advised to try feeding her baby, who had infantile eczema, on goat's milk. One had a cow.

The Institute of Statistics (Oxford) has studied the pattern of food expenditure of families who were asked to keep details of expenditure on food during particular fortnights, for example, in the summer of 1947 , but it was not possible, with our larger numbers, to ask for more than an approximate figure. Whenever practicable, the mother was asked to keep a record for a four-week rationing period and to divide the total by four, but it was not always possible to insist upon this. Sometimes the answer was arrived at by reckoning up how much had been spent at each type of shop. This was often very revealing and gave useful guidance when the quality of an older child's diet was assessed. For instance, the number of loaves bought during the week is fairly indicative of the types of breakfast and high tea, especially if it is also known that the father does not take sandwiches for mid-day, but has a meal at a canteen.

The figure spent on food for the household has been divided by the number of adult-units, each child under ten being counted as half an adult-unit (an approximation of the Cathcart and Murray family coefficient scale).

Table 9 shows remarkably little difference between the social classes, as would be expected in an age of rationing, the average cost of food per adult-unit per week being $16 \cdot 12$ shillings in social classes I-II, $15 \cdot 63$ shillings in social class III, $15 \cdot 18$ shillings in social classes IV-V, and $15 \cdot 62$ shillings in all social classes.

The figures obtained do not relate to any specific week or season during the period 1945-47. At present each family has only been asked for this information once, but several mothers who were first asked in 1945-46 have recently commented that the figure has risen considerably. It is, however, difficult to disentangle how much of this rise is due to the rise in the cost of food itself and how much has been due to the increase in the amount of unrationed foods (especially fruit) for sale in the shops, coupled with the greater amount of money available for food, particularly after demobilization. The amount of money spent on food for the family is now the only item of the budget asked for from

TABLE 9

Distribution by Number of Shillings Spent on Food per Adult-unit Week

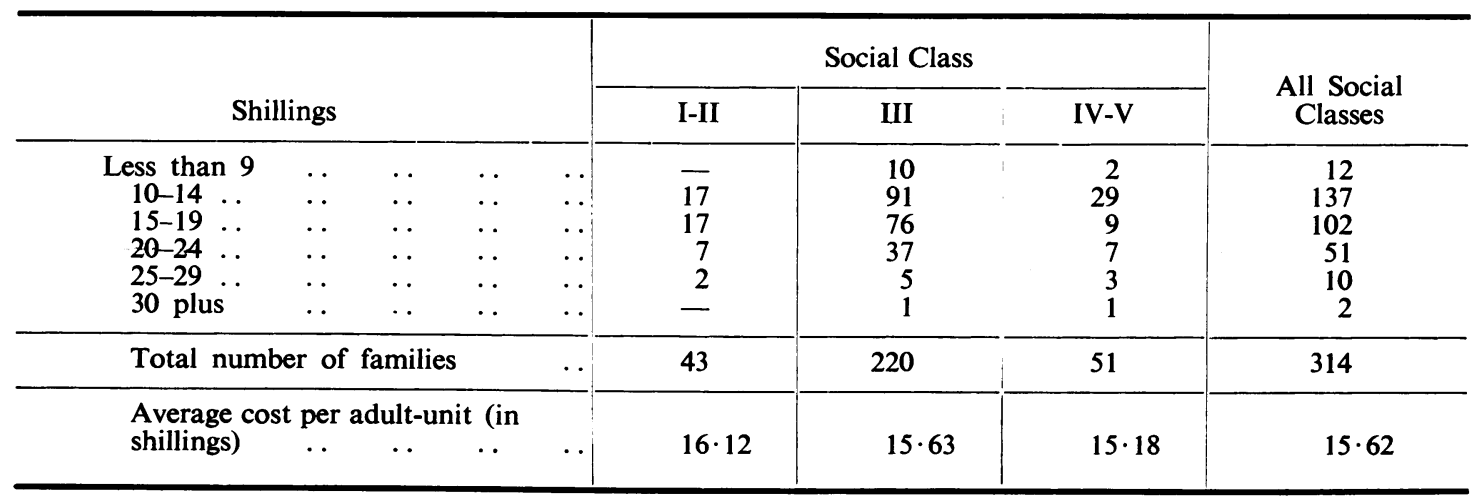


all families. When the survey was first started other items were obtained, but in practice it was found that the figures could not stand comparison statistically. For instance, many of the mothers did not know their husbands' incomes and could only say what they were given for housekeeping, which covered different items of expenditure in different families and so could not be used for comparative purposes. Similarly, although rent was at first asked for, this might mean anything from rent paid for an unfurnished house or payments to a building society, to ' rent' for two furnished rooms which would cover rates and possibly lighting and heating, or else payment to relatives for board and lodging. These figures are of interest when considering individual families, but are of little use when required for statistical comparison, and so are no longer asked for. They are, however, noted when the information is volunteered. For instance, many mothers have commented on the increased rent when the family has been re-housed in a 'prefab' after living in an old house in the centre of the city where the rent was low.

\section{Summary and Conclusions}

It is now generally recognized that deaths in infancy constitute a twofold problem. One phase is represented by stillbirths and neonatal mortality in which obstetrical and nutritional factors are probably of major importance; the other by deaths of babies in the later stages of infancy which are more directly influenced by environment. It seems probable that health and sickness experience and growth and development may also be related to environmental opportunity, and the further purpose of the Oxford survey is to discover what correlations can, in fact, be established. The picture here presented is that of the material conditions surrounding infancy in the main social groups of a city salubrious by comparison with many London boroughs and industrial cities of the North, Midlands, and South Wales. The County Borough of Oxford has for some time returned one of the lowest infant mortality rates in the country. In 1947 the value was 29 , compared with the national figure of 41 per 1,000 live births. In this connexion it is well to remember that Oxford was one of the earliest cities with voluntarily provided maternity and child welfare services before these became the responsibility of the municipality.

In this study the social background of 471 babies, born to mothers of different social groups during the period, has been considered under the following main headings: (a) Material environment (housing, amenities); (b) social and economic environment (parents, occupations, budget); (c) associated human environment (family, household, density); (d) maternal environment (health, efficiency, breastfeeding). The conclusions are as follows.

Material Environment. The majority of the houses were considered to be structurally satisfactory; more than $70 \%$ were free from damp, and for $75 \%$ the ventilation and light were scaled as 'good.' As would be expected, the household amenities varied for the different social groups and this variation reflected the difficulties which the mothers experienced in coping with the baby's requirements. In the overall picture, $30 \%$ of the houses had no bathroom; nearly $40 \%$ had neither a larder nor a refrigerator; good laundry facilities were available only to $44 \%$, and $38 \%$ had outdoor sanitation only.

Associated Human Environment. The density at which the families were living showed an increase in the lower social groups and also confirmed that there was now generally more overcrowding than that disclosed by the 1931 census. Only $45 \%$ of the family units were living on their own. Accordingly, the care and upbringing of the baby was rendered difficult by the interference of too many 'mothers' in the household. Of the 471 families, 220 infants were only children at the time of enquiry, though not necessarily the firstborn, as, in this instance, stillbirths and siblings who had not survived were not considered. There were two children in each of 143 families, from four to nine children in 45 families and more than 10 surviving children in three families. This pattern of distribution accords closely with that for England and Wales in 1946.

Social and Economic Environment. There was a preponderance of children representing social class III in the survey, a result to be expected since this group is numerically the largest in the country generally. Unemployment among the fathers was negligible and 33 mothers were working before the infant was a year old, eight being separated from their children while working. The amount of money spent on food per adult-unit per week varied considerably within the social classes, but between the social classes the average only varied by a shilling. The average for all social classes was $15 \cdot 62$ shillings.

It remains to be seen whether the clinical, somatometric and radiographic studies will reveal any significant differences in respect of the health, sickness, and growth of children in the pre-school years under the diverse environmental opportunities here discussed. 
Thanks are due to the medical officers, health visitors, and the chief sanitary inspector of the Public Health Department of the City of Oxford, and to my colleagues in the Child Health Survey. I am indebted to the late Professor J. A. Ryle and Dr. W. T. Russell for their help and advice in the preparation of this paper.

\section{REFERENCES}

Barnett House Survey Committee (1938). ' Survey of the Social Services in the Oxford District.' Oxford University Press. London.
Cathcart, E. P., and Murray, A. M. T. (1932). Spec. Rep. Ser. med. Res. Coun., Lond., No. 165.

Chadwick, E. (1842). ' Report on the Sanitary Condition of the Labouring Population of Great Britain.' London.

Institute of Statistics (1948). Bulletin, 10, 12.

Mass Observation (1948). Bulletin NS., No. 18.

Sharp, T. (1948). Oxford Replanned. Architectural Press. 